\title{
REG EN PLIG INSAKE ONREGMATIGHEID
}

Dit gaan hier oor die vraag wat die wese van onregmatigheid/wederregtelikheid in privaatregtelike sin is. In die breë kan gekonstateer word dat on regmatigheid 'n kwalifikasie van die juridiese handeling is; en verder dat die onregmatigheid van ' $n$ handeling geleë is in die strydigheid van daardie handeling met 'n gebod of verbod van die positiewe reg. Daaroor bestaan betreklik eenstemmigheid. Maar aangaande die vraag wat in hoofsaak deur spesifiek die privaatreg gebied en verbied word, aan die hand waarvan onregmatigheid in privaatregtelike sin na sy inhoud nader omskryf moet word, loop verskillende opvattinge wyd uiteen.

In die Suid-Afrikaanse regswetenskap staan in dié verband in hoofsaak twee standpunte teenoor mekaar. Die een opvatting lui dat privaatregtelike onregmatigheid wesenlik bestaan in die skending deur A van 'n subjektiewe reg van $\mathrm{B}$; en die ander standpunt gee te kenne dat 'n wederregtelike handeling een is in stryd met ' $n$ regsplig van die dader. Die laasgenoemde sogenaamde ,duty"-leer het onteenseglik sy oorsprong in Engeland en het onder Engelsregtelike invloed in die Suid-Afrikaanse regspraak inslag gevind. Algemeen gesproke word die standpunt deur Engelsregtelik georiënteerde regsgeleerdes verdedig. Diegene in Suid-Afrika, daarenteen, wat hulle beywer vir die behoud van die Romeins-Hollandse grondslae van die SuidAfrikaanse reg en hulle regskundigheid grondves op die tradisies van die kontinentale regswetenskap, stel hulle, algemeen gesproke, op die standpunt van die subjektiewe reg-teorie. En uit laasgenoemde kringe word van tyd tot tyd skerp kritiek gelewer teen die ,duty"-leer.

Die bedoeling is om hier kortliks die twee genoemde standpunte aangaande wederregtelikheid teenoor mekaar te stel en nader te analiseer ten einde self 'n keuse tussen die twee te kan doen. Daarby sal behoorlik rekenskap gegee moet word van die kritiek teen die ,duty"-leer om die geldigheid daarvan op prinsipiële gronde te beproef.

Aldus word langs hierdie weg 'n beskeie bydrae uit die Fakulteit Regte van die P.U. vir C.H.O. tot die reeds omvangryke literatuur oor die „duty"-leer gelewer om saam te val met die eeufeesviering van die Universiteit. Die onderwerp is met die oog hierop geselekteer uit die Privaatreg, omdat die probleme van die Privaatreg telkens die basiese grondslae 
van die reg tref. En spesifiek die „duty"-leer word behandel, omdat dié onderwerp onder meer geleentheid gee vir die kenmerkende teoreties-filosofiese benadering tot die regswetenskap van die Fakulteit Regte van die P.U. vir C.H.O. en kan laat blyk dat die skrywer, in lyn met die tradisie van Afrikaanstalige regsfakulteite, hom ondubbelsinnig skaar aan die kant van diegene wat hulle beywer vir die behoud van die Romeins-Hollandse grondslae van die Suid-Afrikaanse reg, sonder om egter in 'n emosioneel belaaide ekstrimisme kritiek teen alles met 'n Engelsregtelike oorsprong ongeregverdig aan te dik.

Die ,duty"-leer: Ooreenkomstig die ,duty"-leer handel 'n persoon onregmatig as hy versuim om 'n regsplig na te kom. By die eksponente van hierdie teorie soek 'n mens meestal tevergeefs na 'n nadere omskrywing van die aard en inhoud van die bedoelde verpligtinge. McKerron: The law of delict (Kaapstad, 1965) is tot op sekere hoogte hierop 'n uitsondering, vir sover hy naamlik van verskillende soorte regspligte melding maak.

Hy onderskei meer bepaald twee pare regspligte, te wete:

(a) 'n „general duty" teenoor 'n „duty owed to a specific other person or persons"; en

(b) 'n ,duty imposed by law" teenoor 'n ,duty voluntarily assumed".

Hy wend terloops hierdie begrippepare aan om 'n onregmatige daad van kontrakbreuk en die verbreking van 'n kwasie-kontrak te onderskei. En afgesien daarvan definieer hy skuld in terme van 'n sogenaamde ,duty to take care".

Ten einde die juridiese sin van die „duty"-leer te bepaal, word vervolgens kortliks aandag gegee aan die betekenis van hierdie verskillende soorte regspligte.

\section{Die algemene en besondere plig:}

Met hierdie indeling van regspligte laat McKerron blyk dat hy nie onkundig is aangaande die leerstuk van die subjektiewe reg nie. Want hy projekteer hier eenvoudig die tradisionele indeling van subjektiewe regte in absolute en relatiewe regte op regspligte.

McKerron se „general duty”, wat hy omskryf as „a duty owed to persons generally" (a.w., bl. 3), korrespondeer met die sogenaamde absolute subjektiewe reg, wat 'n reg sou wees 
wat teenoor enige of alle ander persone afdwingbaar is. Die "duty owed to a specific other person or persons" korrespondeer weer met die relatiewe subjektiewe reg, wat sogenaamd net teenoor 'n bepaalde ander persoon of persone afdwingbaar is. McKerron gee nou te kenne dat deliktuele onregmatigheid geleë is in die skending van 'n ,general duty", terwyl die onreg. matigheid van kontrakbreuk en die verbreking van 'n kwasiekontrak spruit uit ,a duty owed to a specific other person or persons".

Die Romaniste het met hulle indeling van subjektiewe regte in absolute en relatiewe regte net met die saaklike en die vorderingsreg (die sogenaamde persoonlike reg) rekening gehou. In die Romeinse reg is wel beskerming verleen aan 'n subjek se aanspraak op sy persoonlikheidsgoedere, maar die Romeinse regsgeleerdes het daardie aanspraak nie geëien as 'n besondere soort subjektiewe reg nie. Met die immateriële goedereregte is nie rekening gehou nie, omdat sodanige regte vrywel onbekend was in die Romeinse reg. Die beskerming van immateriële goedereregte is trouens 'n betreklik moderne regsinstelling en word in die Suid-Afrikaanse reg volledig deur wetgewing gereël.

Die ontdekking van die persoonlikheidsregte en die instelling van immateriële goedereregte het egter nie as sodanig enige twyfel gewek aangaande die geldigheid van die tradisionele indeling van subjektiewe regte in absolute en relatiewe regte nie. Want net soos die saaklike reg is hulle eintlik teenoor enige of alle ander persone afdwingbaar en dus, ooreenkomstig die Romanistiese opvatting, absoluut. Maar 'n noukeuriger analise van die vorderingsreg, wat volgens die bedoelde opvatting die enigste relatiewe reg sou wees, het die slotsom laat posvat dat subjektiewe regte nie aldus ingedeel kan word nie. Hierdie slotsom is hier in Suid-Afrika oortuigend bevestig in die proefskrif van $\mathbf{N}$. J. van der Merwe: Die beskerming van vorderingsregte uit kontrak teen aantasting deur derdes.

Die vorderingsreg kan kortweg beskryf word as die aanspraak van 'n krediteur op die prestasie van 'n debiteur. Die Romaniste het met die onderhawige indeling van subjektiewe regte te kenne gegee dat die krediteur sy aanspraak net teen ' $n$ bepaalde persoon (die debiteur) kan afdwing; of anders gestel, hy kan die prestasie alleen van die debiteur en van niemand anders nie opeis. Daarom het hulle hierdie aanspraak 'n relatiewe reg genoem. 
Maar die vorderingsreg het ook ' $n$ ander kant. Die skuldeiser kan naamlik 6ók van derdes iets vorder, met name dat hulle sal toelaat dat die debiteur presteer. Doen enige derde dit nie, maar sou hy op skuldige wyse prestasie deur die debiteur voorkom, bv. deur die onderhoudspligtige debiteur nalatiglik te dood, of die werknemer ongeregverdig af te rokkel van sy werkgewer, pleeg hy 'n onregmatige daad. In dié sin is die vorderingsreg dus ook teenoor enige of alle ander persone afdwingbaar en bly daar eintlik geen relatiewe reg meer oor nie. Daarom is die indeling van subjektiewe regte in absolute en relatiewe regte nie houdbaar nie.

Hierdie kritiek is mutatis mutandis $66 \mathrm{k}$ op McKerron se indeling van regspligte in algemene en besondere pligte van toepassing, want hy probeer nie met daardie indeling enigiets meer te sê as wat die Romaniste met hulle absolute en relatiewe regte te kenne wou gee nie. Daar is net dié verskil dat die pligte, wat McKerron in die oog het, in wese almal besondere pligte moet wees, naamlik pligte van enige persoon teenoor ' $n$ spesifieke reghebbende. Die reghebbende is altyd ' $n$ besondere, meteens aanwysbare persoon, terwyl enige of alle ander persone aan die ander (plig-) kant van die verhouding staan. Die hoofsaak is egter dat sy indeling 'n verouderde regsteorie napraat en self nie deurdag is nie.

\section{Die regsplig en die vrywillige aanvaarde plig:}

McKerron gee vervolgens te kenne dat daar sekere pligte is wat deur die positiewe reg aan jou opgelê word, teenoor ander pligte wat 'n persoon vrywillig op hom neem. Die plig wat deur 'n onregmatige daad en die verbreking van 'n kwasiekontrak geskend word, sê hy, is van die eersgenoemde soort, terwyl kontrakbreuk die skending is van 'n vrywillig aanvaarde plig.

McKerron se bedoeling is wel duidelik, maar sy formulering en terminologie skep die indruk dat die vrywillig aanvaarde plig nie ook 'n juridiese plig is nie. Daarmee gee hy uitdrukking aan die tipiese standpunt van die analitiese positivisme dat alleen die staatlike reg en eintlik ook net die statutereg werklik "law" is. Vir sover McKerron hier 'n onderskeid wil maak tussen pligte wat deur die staatlike reg verorden word aan die een kant; en pligte wat nie-staatlik in die lewe geroep word aan die ander kant, steek daar sin in sy standpunt. Maar 
vir sover hy in sy uiteensetting daarvan te kenne gee dat die nie-staatlike reg nie ,law" is nie, huldig hy 'n versmalde regsbegrip, waarmee glad nie saamgestem kan word nie.

Die belangrike is egter dat McKerron ook hiermee geensins ' $n$ bydrae lewer tot die analise van pligte na hulle wese en inhoud nie. Die plig bly nog as sodanig onomskrewe.

\section{Die plig om voorsorg te tref:}

McKerron omskryf skuld in terme van 'n sogenaamde „duty to take care". In sy analise van nalatigheid haal hy die volgende beskrywing van hierdie soort plig uit die Engelsregtelike gewysde: Bourhill v. Young (1943) A.C. 92; (1942) All E.R. 396 (H.L.) aan:

„The duty to take care is the duty to avoid doing or omitting to do anything the doing or omitting to do which may have as its reasonable and probable consequence injury to others, and the duty is owed to those to whom injury may reasonably and probably be anticipated if the duty is not observed."

Dit is nou weer tipies van McKerron dat hy hierdie sitasie sonder kommentaar onderskryf en hom daardeur blykbaar vereenselwig met die waarskynlikheidsteorie insake kousaliteit wat daarin weerspieël word, terwyl hy hom net daarna op die standpunt van die voorsienbaarheidsteorie stel. Elders in sy werk openbaar McKerron (inkonsekwent) sy aanhang vir ten minste nog twee ander kousaliteitsteorieë, naamlik in verband met medewerkende skuld die beslissende oorsaakteorie en in die algemeen die onmiddellike gevolgeteorie. Maar dit net terloops.

Aangaande die vraag wanneer iemand nou so 'n „duty to take care" het, antwoord McKerron met die beproefde redelike mantoets. Dit toon die omslagtigheid van sy hele benadering. In die Romeins-Hollandse reg word nalatigheid omskryf in terme van die optrede van 'n redelike man. McKerron sê 'n persoon handel nalatig as hy in stryd optree met 'n "duty to take care"; en 'n mens het 'n plig om voorsorg te tref as ' $n$ redelike man onder dieselfde omstandighede voorsorg sou getref het. Langs 'n onnodige omweg kom hy dus tog maar by die gewone toets vir nalatigheid uit. Die bybring van die plig is in dié geval dus geheel en al toutologies.

In verband met opset postuleer McKerron, sonder meer, 
die sogenaamde ,universal obligation" (bl. 46) dat elkeen 'n plig moet hê om nie willens en wetens ' $n$ ander te benadeel nie.

Die vraag is nou of die aanwysing van die onderhawige soort plig enigiets bydra tot die sisteem van regspligte. Die antwoord lê voor die hand: hoewel McKerron verskillende soorte regspligte onderskei, doen hy dit sonder om elkeen daarvan aan ' $n$ vaste betekenismoment te verbind. Van 'n prinsipiële sisteem van regspligte is daar in elk geval by hom geen sprake nie, want die verskillende soorte regspligte word deur hom kursories aangewend om die een regsfiguur van 'n ander te onderskei en nie met die vooropgesette oogmerk om inhoud te gee aan en ' $n$ sisteem te vind van regspligte nie. Die regsplig bly daarom 'n vae onduidelikheid.

\section{Die subjektiewe reg-teorie:}

Die ander standpunt is dat wederregtelikheid geleë is in die aantasting van 'n ander persoon se subjektiewe reg. Vir die wederregtelikheid van so 'n handeling word natuurlik bykomstige vereistes gestel, maar die kern van wederregtelikheid lê opgesluit in die skending van 'n subjektiewe reg.

Gewoonlik word verklaar dat die begrip: „subjektiewe reg" dieselfde betekenis het as dit wat in Engels 'n ,right" genoem word. Dit is nie heeltemal waar nie, want die genoemde Engelse woord is self ryk aan betekenisse, net een waarvan met "subjektiewe reg" korrespondeer. Terwyl die woord „right" 66k gebruik word om die kompetensie van 'n regsubjek om aan die regsverkeer deel te neem (juridiese handelinge te verrig), asook die bevoegdheid van 'n regsubjek om met 'n regsobjek te handel, aan te dui, word die begrip „subjektiewe reg" gereserveer vir die aanspraak van 'n regsubjek teenoor derdes op 'n regsobjek.

Die bedoelde aanspraak impliseer in die eerste plek dat die subjek in ' $n$ bepaalde regsbetrekking te staan kom met die objek waarvan daar sprake is. Hierdie sogenaamde subjekobjekverhouding het tot inhoud dat die objek die subjek toekom, uit hoofde waarvan die subjek bevoeg is om die objek te geniet en daaroor te beskik. Maar die aanspraak van die subjek op die objek impliseer in die tweede plek 606 ' $n$ verhouding tussen die subjek en derdes (ander regsubjekte). Hierdie sogenaamde subjek-subjekverhouding het tot inhoud dat die reghebbende subjek van ander subjekte kan vorder 
om sy aanspraak op die objek te duld. Hy kan van derdes vorder dat hulle niks sal doen wat die uitoefening van sy genots- en beskikkingsbevoegdheid sal belemmer of verhinder nie.

Die derdes het aldus 'n plig om hulle te weerhou van enige handeling wat die uitoefening van die bevoegdhede van 'n subjektief geregtigde persoon sal bemoeilik of verhinder. In dié sin word gewoonlik verklaar dat die een persoon se subjektiewe reg 'n ander persoon se plig impliseer; dat B se plig die teenkant is van A se subjektiewe reg.

In die regswetenskap word meestal vier soorte subjektiewe regte onderskei met die aard van die objek as indelingsbeginsel. As die objek van die persoon se subjektiewe reg 'n stoflike ding (saak) is, word sy subjektiewe reg 'n saaklike reg (w.o. eiendomsreg, besit, servituut en pand- en verbandreg) genoem; die aanspraak van 'n persoon op 'n onstoflike geestesproduk van die mens (immateriële goed) word 'n immateriële goederereg (w.o. patentreg, outeursreg, reg op 'n handelsmerk en -naam, reg op wapens en kleure, reg op klandisiewaarde, ensomeer) genoem; 'n persoon het 'n persoonlikheidsreg op aspekte van sy eie persoonlikheid (die integriteit van sy liggaam, sy goeie naam en sy eergevoel); en die reg van 'n skuldeiser op die prestasie van 'n skuldenaar word 'n vorderingsreg genoem.

Genoeg om te laat blyk dat die regswetenskap vir homself reeds 'n goeie beeld gevorm het van die soorte subjektiewe regte en elkeen na sy inhoud noukeurig geanaliseer het. Wanneer wederregtelikheid daarom in terme van subjektiewe regte gedefinieer word, weet 'n mens presies wat daarmee bedoel word.

Kritiek teen die ,duty"-leer:

Die Suid-Afrikaanse regsliteratuur is ryk aan kritiese opmerkings oor die ,duty"-leer. Aldus word byvoorbeeld verklaar dat die bedoelde leerstuk afkomstig is uit die Engelse reg, wat op ' $n$ heel ander grondslag as die Suid-Afrikaanse reg ingestel is, en dat dit daarom in die eerste plek nog nooit hier tuis gehoort het nie. In aansluiting hierby word verder verklaar dat die bedoelde Engelsregtelike denkbeeld aanleiding gee tot die infiltrasie van ander verwante Engelsregtelike figure, wat dikwels nog minder tuis is in ons eie regstelsel en wat die RomeinsHollandse steunpilare van die Suid-Afrikaanse reg aantas. Van der Merwe en Olivier: Die onregmatige daad in die Suid-Afri- 
kaanse reg (Pretoria, 1966), bl. 78 sonder die feit dat die „duty"leer aanleiding gee tot ' $n$ verwarring tussen wederregtelikheid en skuld uit as die vernaamste beswaar teen die leerstuk.

Al hierdie punte van kritiek is nie sonder meriete nie. Teenoor Van der Merwe en Olivier se „vernaamste beswaar" kan 'n mens miskien opmerk dat die bedoelde verwarring vermy kan word as jy in gedagte hou dat dit by wederregtelikheid gaan om 'n "general duty imposed by law", terwyl skuld geweef word om 'n „duty to take care". En Van der Merwe en Olivier sit in dié verband self in 'n glashuis met klippe en gooi, want hulle worstel ook maar om daardie "redelikheid" wat by wederregtelikheid ter sprake kom te onderskei van die "redelikheid" wat as die toets vir nalatigheid diens moet doen.

Dit egter net terloops. Die aandag moet hier gevestig word op die betreklik algemene beswaar dat die „duty"-leer „verkeerd" is; dat dit „verkeerde resultate” oplewer en daarom verwerplik is.

Indien ' $n$ mens aanvaar dat ' $n$ regsplig in die Privaatreg die teenkant is van 'n subjektiewe reg (en dit word algemeen só aanvaar), dan spreek dit eintlik vanself dat die twee onderhawige standpunte aangaande wederregtelikheid presies op dieselfde neerkom; dat die verskil tussen die twee standpunte eintlik net ' $n$ kwessie van benadering is. Die een omskryf wederregtelikheid van die kant van 'n reghebbende subjek, terwyl die ander dieselfde regsfiguur net van die ander kant, van die kant van die pligtige persoon, beskou. En as die een beskouing „verkeerd" is, moet die ander beskouing 66k verkeerd wees, want albei sienswyses is met dieselfde regsfiguur (bloot van verskillende kante besien) besig.

Kortom, bloot op die keper beskou, kan die „duty"-leer nie in beginsel verwerp word, terwyl die subjektiewe regteorie aangaande wederregtelikheid aangehang word nie. Maar daar is beslis praktiese besware teen die „duty"-leer, welke besware spruit uit die reeds genoemde gebrek aan 'n behoorlike insig in die struktuur van regspligte. Daardie gebrek aan insig word onder meer óók deur McKerron, die mees verbete en konsekwente eksponent van die "duty"-leer in Suid-Afrika, aan die dag gelê. McKerron maak naamlik uitsonderings op die "duty"leer met voorbeelde wat inderdaad nie uitsonderings is nie. Maar die feit dat hy met die bedoelde voorbeelde oor sy eie "duty"-leer struikel, moet hom nie verkwalik word nie, want 'n mens kom eers agter dat hulle geen uitsonderings is nie 
as jy die voorbeelde ondersoek met die oog op die subjektiewe reg wat aangetas word.

Die eerste geval wat vir McKerron probleme oplewer, het betrekking op die eis van die afhanklike. A en B is met mekaar getroud en nou word $\mathrm{A}$, die broodwinner, nalatiglik deur $\mathrm{C}$ gedood. Dit is 'n bekende reël van die reg dat B skadevergoeding van $C$ kan verhaal vir haar verlies aan onderhoud. Maar waar, vra McKerron, lê C se „duty"? B eis vir haar verlies aan onderhoud. Sy slaag in haar eis teen $\mathrm{C}$ hoewel $\mathrm{C}$ geen plig het om haar te onderhou nie. Siedaar! 'n Uitsondering op die ,duty"leer. $\mathrm{C}$ het wederregtelik teenoor $\mathrm{B}$ opgetree hoewel hy geen plig teenoor haar het nie.

Bekyk 'n mens egter dieselfde voorbeeld van die ander kant, sien jy gou die fout in McKerron se argument. Dit gaan hier om B se vorderingsreg op onderhoud wat aangetas is. En nou weet 'n mens uit die wetenskaplike analise van die struktuur van die vorderingsreg dat daardie reg nie net teen die skuldenaar ( $A$ in ons voorbeeld) afdwingbaar is nie, maar dat $B$ van alle derdes (insluitende $C$ ) kan vorder om niks te doen wat $A$ sal verhinder om sy prestasie te lewer nie. $C$ het dus 'n plig teenoor B, naamlik die plig om nie te voorkom dat A sy prestasie aan B lewer nie. Daardie plig word geskend indien $\mathrm{C}$ vir A nalatiglik dood.

In 'n ander voorbeeld skets McKerron die geval waar A aan $\mathrm{C}$ toestemming gegee het om hom te benadeel, of toegestem het om die risiko van benadeling deur ' $n$ handeling van $C$ te loop. Indien $\mathrm{A}$ nou deur die betrokke handeling van $\mathrm{C}$ beseer word kan hy nie vergoeding van $\mathrm{C}$ verhaal nie, want volenti non fit iniuria. Maar as A deur dieselfde handeling gedood word, kan B, sy afhanklike, nogtans skadevergoeding van C met die eis van die afhanklike verhaal.

McKerron argumenteer hieroor soos volg: $\mathrm{C}$ het inderdaad 'n plig teenoor A om hom nie te beseer of te dood nie. Maar $A$ het met sy toestemming vir $C$ van daardie plig onthef. Nogtans slaag $\mathrm{B}$ se aksie teen $\mathrm{C}$ hoewel hy van die bedoelde plig bevry is.

Van die kant van die reghebbende subjek gesien is dit meteens duidelik dat dit hier nie gaan om A se persoonlikheidsreg wat met sy toestemming aangetas is nie. B grond haar eis op die aantasting van haar vorderingsreg op onderhoud. Hoewel A van sy eie regte afstand kan doen, kan hy nie van iemand anders se regte afstand doen nie. B se vorderingsreg 
het geldig gebly; en soos reeds aangetoon is, kan sy daardie reg óok teen $\mathrm{C}$ handhaaf en staan $\mathrm{C}$ ook as pligtige persoon teenoor haar in ' $n$ verhouding.

Kortom, die uitsonderings wat McKerron op die „duty"leer maak, is inderdaad nie uitsonderings nie. Dit is egter te verstane dat McKerron dit nie aldus ingesien het nie, omdat 'n mens eers met 'n konstruksie van die subjektiewe reg op die spoor van die regte verhouding tussen die betrokke persone kom. Juis omdat regspligte nie behoorlik geanaliseer en na hulle inhoud gepresiseer is nie, is dit dikwels moeilik om die toepaslike plig te vind as jy die korrelate reg buite rekening laat.

Maar juis daarom propageer ons hier die subjektiewe regbenadering met betrekking tot wederregtelikheid, omdat dit prakties meer dienlik is om die onregmatigheid van ' $n$ han. deling te bepaal.

P.U. vir C.H.O.

J. D. van der Vyver. 